\title{
Study of Changes to the Organic Functional Groups of a High Volatile Bituminous Coal during Organic Acid Treatment Process by FTIR Spectroscopy
}

\author{
B. Manoj", Ponni Narayanan \\ Department of Physics, Christ University, Karnataka, India \\ Email: ${ }^{*}$ manoj.b@christuniversity.in
}

Received November 1, 2012; revised December 16, 2012; accepted January 4, 2013

\begin{abstract}
A high volatile bituminous coal was subjected to a series of organic acid treatment in steps using citric acid (1 hr and 2 hr) and buffered EDTA with acetic acid (1 to $3 \mathrm{hr}$ ) at room temperature. Leaching was performed with acetic acid (2N) also for $1 \mathrm{hr}$. Citric acid procedure reduced the mineral matter below 1.94\%. Calcites and aluminates are completely removed along with substantial quantity of silicates by citric acid leaching. The change in absorption of organic functional groups and mineral matter in coal samples were studied using Fourier transform infrared spectroscopy (FTIR). Analysis indicated that oxygen containing species were decreased in the coal structure during acetic acid and citric acid (40\%) procedure and buffered EDTA 3 hours leaching. As the period of leaching with buffered EDTA increased from 1 $\mathrm{hr}$ to $3 \mathrm{hr}$, organic functional groups and mineral functional groups decreased its intensity. The results indicated that the described acid treatment procedures with citric acid have measurable effects on the coal structure.
\end{abstract}

Keywords: Leaching; Bituminous Coal; Minerals; FTIR

\section{Introduction}

Fossil fuel constitutes an imperative fraction of natural fuel resources available at present. Coal is the most abundant non-renewable energy source of fossil origin. Mineral matter and sulfur in coal place huge precincts on its use. Furthermore, apprehensions over the effects of excessive burning of coal worldwide on the climate have restricted mankind from extracting its full potential. The elimination of mineral matter from coal has been practiced since coal was first extracted from the earth and researches in chemical demineralization have been extensively conducted from decades. But the processes have not reached widespread commercialization due to the fact that the methods for removing mineral matter need to have low cost and be environmentally friendly. Methods of removing metal ions from ore mainly consist of physical, chemical and biological technologies. The acceptance of coal for particular process in industry critically depends on its organic and inorganic constituents. The organic structure of consist of heterogeneous aromatic structures, with aromaticity increasing from low to high rank coals. The organic part of coal contains sulphur, oxygen and nitrogen in functional groups in addition to carbon. Fourier Transform Infrared (FTIR) spectroscopy is a widely used analytical technique for deter-

"Corresponding author. mining the different functional groups of a coal structure. This method is capable to reveal aromatic and aliphatic carbohydrogenated structures and hetroatomic functions (oxygenated), as well as mineral functional groups in coal.

In the present study, FTIR spectra of high volatile bituminous coal from Korba coal fields, India, were obtained in order to investigate the chemical structure of these medium rank coals, as well as their chemical leached products. The effect of carboxylic acid leaching on coal structure and the mechanism of mineral solubilization is discussed.

Acharya et al. [1] studied the reaction mechanism of bioleaching of manganese ore with manganese reducing fungi Penicillium citrium and various acids such as oxalic acid, citric acid and sulphuric acid. The microbial solubilization of some Indian bituminous coal carried out by Sharma and Wadhwa [2] also revealed the removal of minerals by mixed culture of bacterium. It is known that the micro organisms secrete acids during leaching and these lowers the $\mathrm{pH}$ of the solution and enhances the removal of minerals by reducing the cohesive force between minerals and coal matrix.

\section{Experimental}

\subsection{Coal Sample}

An Indian bituminous coal, Korba $(\mathrm{K})$ coal, was used in 
this study. The bituminous coal was air-dried and ground to the particle size $<75 \mu \mathrm{m}$. The ultimate and proximate analysis is presented in Table $\mathbf{1}$, and the ash content is $8.2 \mathrm{wt} \%$ on a dry basis.

\subsection{Demineralization}

The Korba bituminous coal was demineralized using different carboxylic acids like citric acid and acetic acid. $10 \mathrm{~g}$ of coal was mixed with $50 \mathrm{ml}$ of citric acid (40\%$1 \mathrm{hr}$ and $2 \mathrm{hr}-\mathrm{KC} 1$ and $\mathrm{KC} 2$ ) and acetic acid (2N-KA) individually in a $500 \mathrm{ml}$ Teflon beaker. The mixture was stirred for $1 \mathrm{~h}$ at $30^{\circ} \mathrm{C}$. The mixture was kept for $24 \mathrm{hr}$ and after leaching; the treated coal sample was separated from the respective organic acid solution by filtration using a poly-propylene funnel and naturally dried at room temperature. The coal resulting samples were washed repeatedly with double distilled water to remove the acid content, dried in an oven at $70^{\circ} \mathrm{C}$ and allowed to cool slowly in a dessicator. The sample was treated with buffered EDTA with acetic acid for a period of 1, 2, and 3 hours (KAE1, KAE2 and KAE3), filtered and dried as discussed above (3 - 5).

\section{Results and Discussion}

\subsection{Spectral Analysis of the Coal Sample}

The identification of the most prominent bands of FTIR spectra of both bituminous coal and its chemical leached products are shown in Table 1.

Intense bands are observed at $540 \mathrm{~cm}^{-1}$ (Figures 1 and 2), resulting from clay and silicate minerals, and at 3618 - $3628 \mathrm{~cm}^{-1}$ and $3696-3700 \mathrm{~cm}^{-1}$, attributed to kalonite and illite minerals [3]. These bands became more evident in the FTIR spectra of solid residues of leached coal. The most intense peaks at $3600-3800 \mathrm{~cm}^{-1}$ region present in the samples $\mathrm{KC}$ and $\mathrm{KA}$, may be attributed to the presence of clay minerals. This is present even after leaching, but with decreased intensity. In Figure 1 all the absorp-

Table 1. FTIR band assignment of virgin and leached coal samples.

\begin{tabular}{ll}
\hline Bands $\left(\mathrm{cm}^{-1}\right)$ & Assignment \\
\hline 540 & Clay and silicate minerals \\
669 & Aromatic out of plane C-H deformations \\
$1032-1090$ & Silicate minerals \\
1375 & Stretching modes of methyl group \\
1600 & C=C aromatic stretching \\
2851 & Aliphatic symmetric $-\mathrm{CH}_{2}$ stretching \\
2920 & Aliphatic asymmetric $-\mathrm{CH}_{2}$ stretching \\
$3618-3620$ & Clay minerals \\
$3696-3700$ & Kaolinite and illite minerals \\
\hline
\end{tabular}

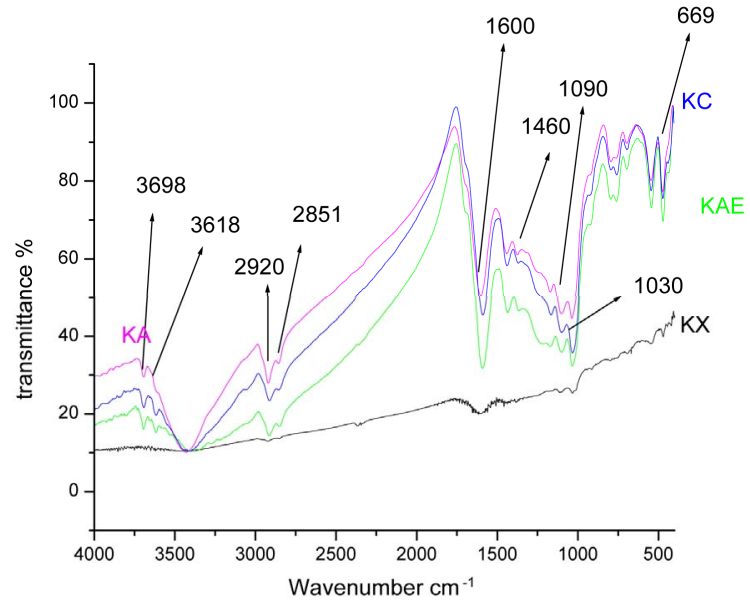

Figure 1. FTIR spectra of virgin and leached coal samples. KX-Virgin bituminous coal, KA-Acetic acid leached coal, KC-Citric acid leached coal, KAE-Buffered EDTA leached coal.

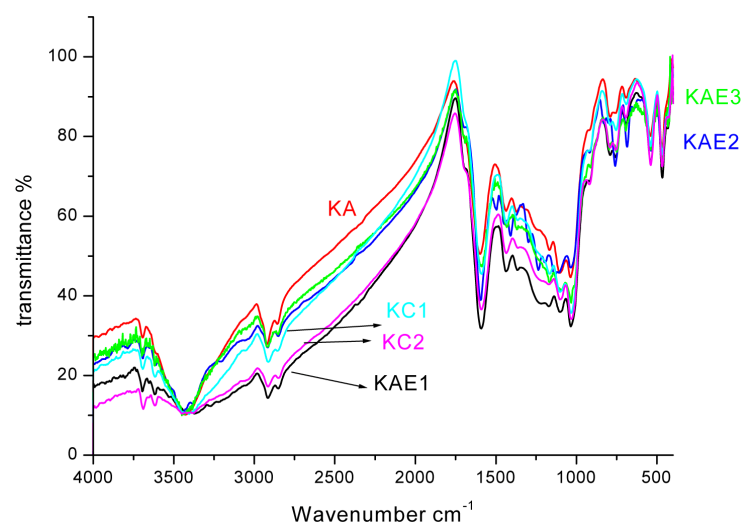

Figure 2. FTIR spectra of chemical leached samples KAAcetic acid leached coal, KC1-Citric acid leached (1 hr), KC2-Citric acid leached (2 hr), KAE1-Buffered EDTA leached (1 hr), KAE2-Buffered EDTA leached (2 hr), KAE3-Buffered EDTA leached (3 hr).

tion bands are unresolved indicating that the material constituents have either large particle size or contain polymeric units.

There is a broad and strong band observed in all the samples at $3640 \mathrm{~cm}^{-1}$ which can be attributed to hydroxyl stretching vibrations. This is well reflected from the observations of Osawa and Shih [4], Subkowiak et al. [5], and Chomnanti et al. [6] in the case of coal oil shale and lignite samples. The bands at $2800-2920 \mathrm{~cm}^{-1}(\mathrm{C}-\mathrm{H}$ aliphatic stretching) and $1375-1465 \mathrm{~cm}^{-1}$ (C-H aliphatic bending) are almost same in all treated samples. Sharp intense bands observed at 2920 and $2850 \mathrm{~cm}^{-1}$ in all the samples can be attributed to the presence of valency oscillations of $\mathrm{CH}_{3}$ and $\mathrm{CH}_{2}$ aliphatic groups. This may also arise due to the stretching vibration from $-\mathrm{CHO}$ group as reported by Manoj et al. [7].

Chomnanti et al. [6] observed similar sharp bands at 
2900 and $2830 \mathrm{~cm}^{-1}$ in the case of tertiary lignites. These bands arise due to aromatic- $\mathrm{CH}$, aliphatic- $\mathrm{CH}$ and $\mathrm{C}=\mathrm{C}$ aromatic groups respectively. The intensity of the bands directly gives the percentage of carbon content in the sample. In very low rank coals the intensity of $2920 \mathrm{~cm}^{-1}$ is found to be very small due to the fact that the proportion of the aliphatic - $\mathrm{CH}$ hydrogen is substituted by hydroxyl groups.

Supaluknari et al. [9] observed the bands at 1720 and $1610 \mathrm{~cm}^{-1}$ in the case of brown coals and oxygen rich subbituminous coals, while in higher rank coals with low oxygen content the absorption at $1720 \mathrm{~cm}^{-1}$ appears as a shoulder on the $1610 \mathrm{~cm}^{-1}$ band. With leaching the oxygen content is decreased. There is a small absorption in the spectrum of samples leached with organic acids especially citric acid and acetic acid. Such a result is in conformity with the observations of Supaluknari et al. [9] in the case of oxygen rich Australian Brown coals.

Low and Glass [10] made elaborate discussion of 1600 $\mathrm{cm}^{-1}$ band of carbons. They assigned the band in case of low temperature carbons in low rank coals and chars which have been formed at relatively low temperature, to aromatic ring stretch of small, discrete aromatic entities. They also suggested that the oxygen containing structure may or may not be involved in the formation of 1600 $\mathrm{cm}^{-1}$ band. This band becomes very distinct and increases with leaching. This is a clear indication of increase in carbon content with organic acid leaching $[11,12]$. This is in good agreement with the elemental analysis carried out by EDS (Table 1).

Weak broad bands at $1375 \mathrm{~cm}^{-1}$ and weak shoulder at $1030 \mathrm{~cm}^{-1}$ has been observed in all the samples. Unresolved plateau like bands observed in this region shows that the coal samples constitute complex polymeric materials. This region shows drastic change with organic acid leaching. This is an indication that complex reaction has taken place and many bands became very clear and distinct. The band at $1375 \mathrm{~cm}^{-1}$ is normally present in low rank coals [12]. The intensity of this band decreases in the solubilized product. This indicates that the leaching has improved the quality of fuel. The weak broad bands observed at $1375 \mathrm{~cm}^{-1}$ can be assigned to stretching modes of methylene and methyl groups present in the samples $[7,8]$.

The weak broad bands observed at $1030 \mathrm{~cm}^{-1}$ can be jointly attributed to $\mathrm{C}-\mathrm{O}$ stretching of phenolic hydroxyl groups and trace amount of silicate minerals associated with the lignite samples respectively. This is evident from the fact that $1030 \mathrm{~cm}^{-1}$ band is prominent in the spectrum. With leaching, the silicate bands decreases its intensity. This is an indication of removal of minerals with leaching. But still mineral absorption peaks are very distinct. This is an indication that even though mineral content is decreased with leaching it fails to remove silicates and aluminates totally from the sample. This might be due to the inherent nature of minerals in the coal matrix.

From the above observations it is inferred that the Korba high volatile bituminous coal samples constitute high moisture content. Further, presence of clay minerals with medium carbon content reveals they are medium rank coals.

Figure 2 represents is the spectral graph of sample leached with buffered EDTA of different leaching period along with citric acid and acetic acid treated sample. The silicate and kaolinite bands showed a systematic decrease with increase in leaching time with buffered EDTA treatment. Oxygenated functional groups in the region $1000-1800 \mathrm{~cm}^{-1}$ and aliphatic stretching bands (2850 $3000 \mathrm{~cm}^{-1}$ ) exhibit a decrease in intensity with increase in time of leaching. Comparing the spectral graph it is found that Acetic acid treatment, Citric acid (1 hr) and buffered EDTA ( $3 \mathrm{hrs}$ ) are effective in this region.

\subsection{Characterization of the Demineralized Coal}

Figure 3 shows the sulphur and mineral content in Indian bituminous coal and its demineralized products. When the coal is leached with acetic acid, citric acid and buffered EDTA individually, the sulphur content was nil. Other elements such as calcites are removed completely where as silicates and aluminates are reduced considerably.

The calcites mineral is completely removed by forming calcium acetate complexes and aluminum minerals are removed partially with the formation of aluminium acetate. The expected dissolution reaction is as follows.

$$
\begin{aligned}
& \mathrm{CH}_{3} \mathrm{COOH} \rightarrow \mathrm{CH}_{3} \mathrm{COO}^{-}+\mathrm{H}^{+} \\
& 2 \mathrm{CH}_{3} \mathrm{COO}^{-}+\mathrm{Ca}^{2+} \rightarrow \mathrm{Ca}\left(\mathrm{CH}_{3} \mathrm{COO}\right)_{2}
\end{aligned}
$$

(Calcium Acetate)

Elemental analysis revealed that $\mathrm{Al}$ content was changed from an initial value of $0.95 \%$ to $0.23 \%$ with acetic acid leaching possibly by forming aluminum acetate.

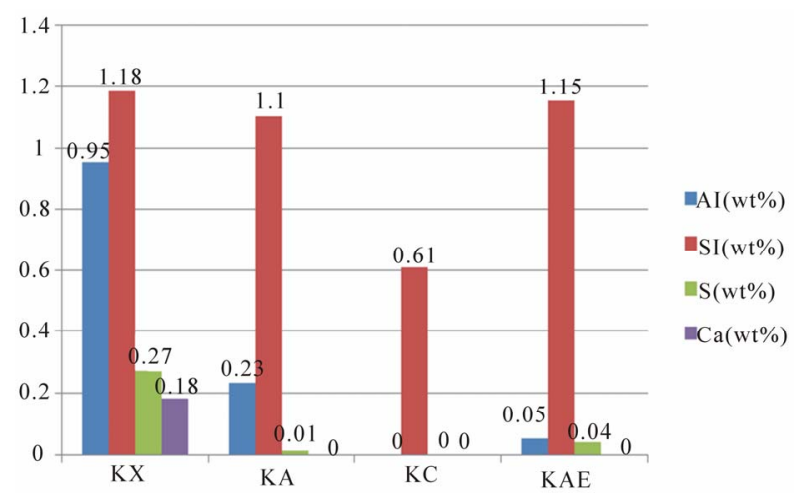

Figure 3. Mineral content in virgin and leached coal samples. 


$$
\begin{aligned}
& \mathrm{CH}_{3} \mathrm{COOH} \rightarrow \mathrm{CH}_{3} \mathrm{COO}^{-}+\mathrm{H}^{+} \\
& 3 \mathrm{CH}_{3} \mathrm{COOH} \rightarrow 3 \mathrm{CH}_{3} \mathrm{COO}^{-}+3 \mathrm{H}^{+} \\
& 3 \mathrm{CH}_{3} \mathrm{COO}^{-}+\mathrm{Al}^{3+} \rightarrow \mathrm{Al}\left(\mathrm{CH}_{3} \mathrm{COO}\right)_{3}
\end{aligned}
$$

(Aluminum acetate)

When the coal sample is leached with citric acid, there is a drastic reduction in mineral content. Estimation of the elemental composition

$(\mathrm{Si}=0.61 \mathrm{wt} \%, \mathrm{Al}=$ nil, $\mathrm{Ca}=$ nil, $\mathrm{S}=$ nil $)$ shows remarkable decrease of Silicates and total removal of Aluminum and Calcites by forming their respective complexes. The efficiency of citric acid and oxalic acid in the demineralization of aluminum was reported by Ghorbani et al. [13] earlier. Citric acid is a tricarboxylic acid and contains three carboxylic groups and one hydroxyl group as possible donor of protons $\left(\mathrm{H}^{+}\right)$at $25^{\circ} \mathrm{C}$. When alumina cation $\left(\mathrm{Al}^{3+}\right)$ are present in the coal and citric acid is fully dissociated in aqueous solution, a complexation reaction may take place.

$$
\begin{aligned}
& \mathrm{C}_{6} \mathrm{H}_{8} \mathrm{O}_{7} \rightarrow\left(\mathrm{C}_{6} \mathrm{H}_{5} \mathrm{O}_{7}\right)^{3-}+3 \mathrm{H}^{+} \\
& \left(\mathrm{C}_{6} \mathrm{H}_{5} \mathrm{O}_{7}\right)^{3-}+\mathrm{Al}^{3+} \rightarrow \mathrm{Al}\left(\mathrm{C}_{6} \mathrm{H}_{5} \mathrm{O}_{7}\right)
\end{aligned}
$$

(Aluminium citrate)

$$
\begin{aligned}
& 2\left(\mathrm{C}_{6} \mathrm{H}_{8} \mathrm{O}_{7}\right) \rightarrow 2\left(\mathrm{C}_{6} \mathrm{H}_{5} \mathrm{O}_{7}\right)^{6-}+6 \mathrm{H}^{+} \\
& 2\left(\mathrm{C}_{6} \mathrm{H}_{5} \mathrm{O}_{7}\right)^{6-}+3 \mathrm{Ca}^{2+} \rightarrow \mathrm{Ca}_{3}\left(\mathrm{C}_{6} \mathrm{H}_{8} \mathrm{O}_{7}\right)_{2}
\end{aligned}
$$$$
\text { (Calcium Citrate) }
$$

The Aluminum and Calcium citrate complexes are precipitated as white precipitate and removed from the sample by washing with water and filtration. The Oxygen content also shows an increase of $18 \%$. Calorific value shows an increase of $10 \%$ after leaching. Sulphur is wholly removed when leached with this reagent.

An attempt is made to exacerbate and stimulate the leaching with buffered EDTA with acetic acid. The FTIR analysis reveals that the leaching could not remove the mineral content completely [14]. From the EDS analysis it is confirmed that the calcites content is nil but the $\mathrm{Al}$ and silicates content was more compared to citric acid leaching $(\mathrm{Al}=0.65 \mathrm{wt} \%, \mathrm{Si}=1.13 \mathrm{wt} \%, \mathrm{~S}=0.04 \mathrm{wt} \%)$. The reason might be some of the mineral phases have got dissolved at the selected $\mathrm{pH}(\mathrm{pH} 4)$ and have redeposited on the surface instead of their extraction. Oxygen content reported an increase of $42 \%$ accompanied by a reduction in calorific value $(8 \%)$ with buffered EDTA leaching. FTIR spectral analysis shows that as the period of leaching increases from 1 to 3 hours, the mineral bands shows a systematic decrease with buffered EDTA leaching. Ash content in the coal sample is reduced marginally from $8.2 \%$ to $7.6 \%$ with KAE3 leaching.

Results of ash analysis and elemental analysis along with Higher Heat Value (HHV) of the coal and its leached products are shown in Figure 4. The ash content

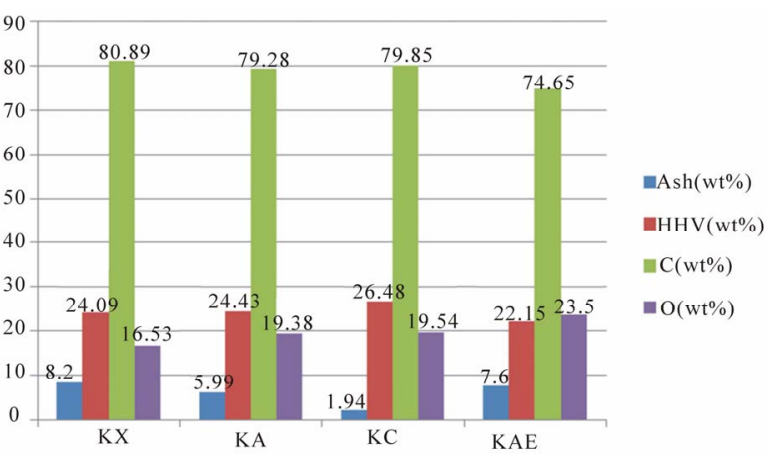

Figure 4. Comparison of virgin and chemical leached coals.

ranges between 8.2 and $1.94(\mathrm{db})$ and oxygen content between 16.53 and 19.54 (daf). Sample KC and KA does not change its carbon content $(79.85 \%$ and $79.28 \%$ respectively). HHV is also preferentially increased with Citric acid leaching. It indicates that oxidation has not happened to coal under study. With buffered EDTA leaching, oxygen content is reported an increase of $42.2 \%$ with a reduction in calorific value.

\section{Conclusion}

Calcites and Aluminates are completely removed by Citric acid along with substantial removal of Silicates. Investigation indicates that oxygen containing species are decreased in the coal structure during acetic acid and citric acid (40\%) procedure and buffered EDTA 3 hour leaching. As the period of buffered EDTA leaching increased from 1hour to 3 hours organic functional groups and mineral functional groups decreased in intensity. The results indicated that the described acid treatment procedures with citric acid have measurable effects on the coal structure. Citric acid procedure reduced the ash content to less than $1.94 \%$. The possible reaction mechanism of silicate, calcites and aluminum leaching with acetic acid and citric acid is discussed.

\section{REFERENCES}

[1] C. Acharya, R. N. Kar and L. B. Sukla," Studies on Reaction Mechanism of Bioleaching of Manganese," Minerals Engineering, Vol. 169, No. 10, 2003, pp. 10271030. doi:10.1016/S0892-6875(03)00239-5

[2] D. K. Sharma and G. Wadhwa, "Demineralization of Coal by Stepwise Bioleaching: A Comparative Study of Three Indian Coals by Fourier Transform Infra Red and X-Ray Diffraction Techniques," World Journal of Microbiology and Biotechnology, Vol. 13, No. 1, 1997, pp. 29-36. doi:10.1007/BF02770804

[3] B. Manoj and A. G. Kunjomana, "Chemical Leaching of an Indian Bituminous Coal and Characterization of the Products by Vibrational Spectroscopic Techniques," International Journal of Minerals Materials and Metallurgy, Vol. 19, No. 4, 2012, pp. 279-283. 
[4] Y. Osawa and J. W. Shih, "Infra-Red Spectra of Japanese Coal: The Absorption Bands at 3450 and 1260 $\mathrm{cm}^{-1}$," Fuel, Vol. 50, No. 1, 1971, pp. 53-57. doi:10.1016/S0016-2361(71)81019-0

[5] M. Sobkowiak and P. C. Painter, "Determination of the Aliphatic and Aromatic CH Contents of Coals by FT-i.r.: Studies of Coal Extracts," Fuel, Vol. 71, No. 10, 1992, pp. 1105-1125. doi:10.1016/0016-2361(92)90092-3

[6] S. Chomnanti, P. Deemak, A. F. Gaines, K. Kasomson, K. Keowkamnerd, V. Lorvidhya, C. Pomilying, N. Sucharitakul, V. V. Witsuksomba and W. Wiroyamon, "A Study of an Oil Shale,” Fuel, Vol. 49, No. 2, 1970, pp. 188-196. doi:10.1016/0016-2361(70)90039-6

[7] B. Manoj and A. G. J. Kunjomana, "Chemical Solubilization of Coal Using HF and Characterization of Products by FTIR, FT Raman, SEM and Elemental Analysis," Mineral Material Characterization and Engineering, Vol. 9, No. 10, 2010, pp. 919-928.

[8] A. N. Mohan and B. Manoj, "Synthesis and Characterization of Carbon Nanosphere from Hydrocarbon Soot," International Journal of Electrochemical Sciences, Vol. 7, 2012, pp. 9537-9549.

[9] S. Supaluknari, F. P. Larkins, P. Redlich and W. R. Jackson, "An FTIR Study of Australian Coals: Characterization of Oxygen Functional Groups," Fuel Processing
Technology, Vol. 19, No. 2, 1988, pp. 123-140.

[10] M. J. D. Low and A. S. Glass, "The Assignment of the $1600 \mathrm{~cm}^{-1}$ Mystery Band of Carbons," Spectroscopy Letters: An International Journal for Rapid Communication, Vol. 22, No. 4, 1983, pp. 417-429. doi: $10.1080 / 00387018908053891$

[11] B. Manoj and A. G. Kunjomana, "Study of Stacking Structure of Amorphous Carbon by X-Ray Diffraction Technique," International Journal of Electrochemical Sciences, Vol. 7, No. 4, 2012, pp. 434- 444.

[12] B. Manoj and A. G. Kunjomana, "Structural Characterization of Selected Indian Coals by X-Ray Diffraction and Spectroscopic Technique," Journal of Applied Scientific Research, Vol. 7, No. 6, 2012, pp. 421-433.

[13] Y. Ghorbani, M. Oliazadeh, A. Shavedi, R. Roohi and A. Pirayehgar, "Use of Some Isolated Fungi in Biological Leaching of Aluminum from Low Grade Bauxite," African Journal of biotechnology, Vol. 6, No. 11, 2007, pp. 1284-1288.

[14] B. Manoj, A. G. Kunjomana and K. A. Chandrasekharan, "Chemical Leaching of Low Rank Coal and Its Characterization Using SEM/EDAX and FTIR," Journal of Minerals \& Materials Characterization \& Engineering, Vol. 8, No. 10, 2009, pp. 821-832. 